\title{
تعليم المفردات باستخدام الصوار والنماذج الإستقرائية (PWIM) لترقية قدرة التلاميذ على الإنشاء الموجه
}

\section{Acep Hermawan ${ }^{1}$ \\ Ghisni Kautsar ${ }^{2}$}

\section{ملخص البحث}

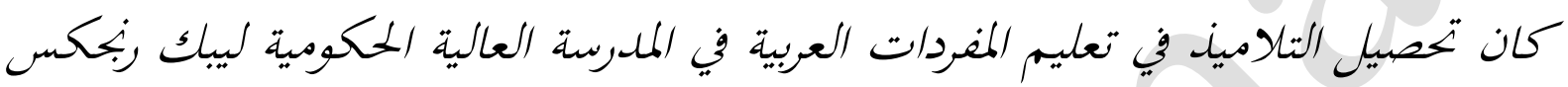
بيتونج بانتين منخغضة. ويغلب عن الظن أن العوامل التي تسبب إليها هي الخلفية التربوية والاهتمام والد فا عية للدي التلامين واراء معظم التلامين. يكتاج الملدرس في تعليم المفردات العربية ؤثثه على الإنشاء الموجه الى الوسيلة المناسب باستخدام الوسيلة الصوار والنماذج الإستقرائية. والأغراض لهذا البحث هي لمعفة قدرة التلاميذ على الإنشاء الموجه قبل استخدام الصور والنماذج الإستقرائية في تعليم المغردات العربية وبعد استخدامها. والطريقة المستخلدمة هي الطريقة التجريبية بتصميم مجموعة واحلة الاختبار القبلى و الاختبار البعلي. ومن النتائج المحصول هي قلرة التلاميذ على الإنشاء الموجه قبل استخدام الصور والنماذج الإستقرائية في تعليم المفردات العربية تلدل على على درجة "منخفصة" بقيمة م 1،، • ه . واما قدرة التلاميذ على الإنشاء الموجه بعد استخدام الصوار

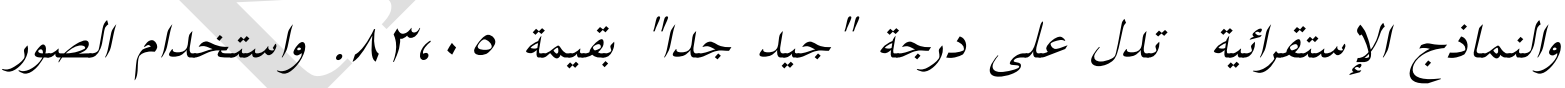
والنماذج الإستقرائية في تعليم المفردات العببية يؤثر في قدرة التلاميذ على الإنشاء الموجه. الكلمات المغتاحية: الإنشاء الموجه، تعليم المفردات، الصوار والنماذج الإستقرائية.

\section{Abstract}

Based on student learning outcomes in learning Arabic vocabulary at MAN 1 Lebak Rangkasbitung Banten which is low. And the factors that cause the low is the background

\footnotetext{
1 Universitas Islam Negeri Sunan Gunung Djati Bandung, acepher@uinsgd.ac.id.

2 Universitas Islam Negeri Sunan Gunung Djati Bandung, kghisni@gmail.com.
} 
of students, interests and talents, student motivation. Therefore, teachers need the right media to achieve the main goal in learning Arabic vocabulary, its effect on guided writing using Picture Word Inductive Model media. The purpose of this study was to determine the students' ability in guided writing before and after using the Picture Word Inductive Model method, and to determine the improvement of student learning outcomes. The method used in this research is the experimental method of pretest and posttest design models. The result of the research is that student learning outcomes in guided writing before using the Picture Word Inductive Model method show the "Less" value category with a value of 50.83. The results after using the Picture Word Inductive Model are "Very Good" with a value of 83.05. And the use of Picture Word Inductve Model in Arabic vocabulary learning has an influence on students' ability in guided writing.

Keywords: Arabic Vocabulary, Guided Writing, Picture Word Inductive Model.

\section{المقدمة}

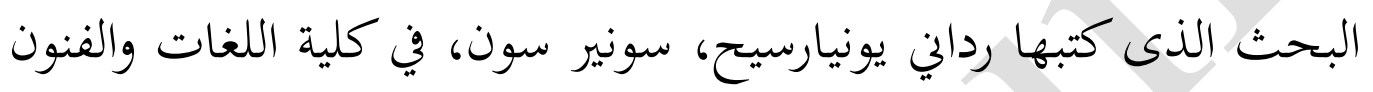

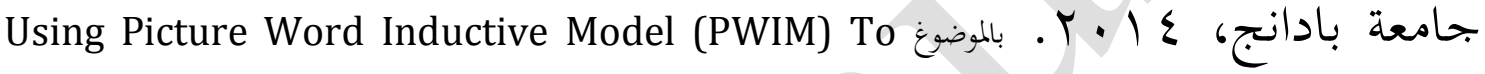

Teach Junior High School Students In Writing a Descriptive Text. Radani Yuniyarsih, Saunir Saun. English Departement. Faculty of Languages and Arts State

Univrtsity of Padang
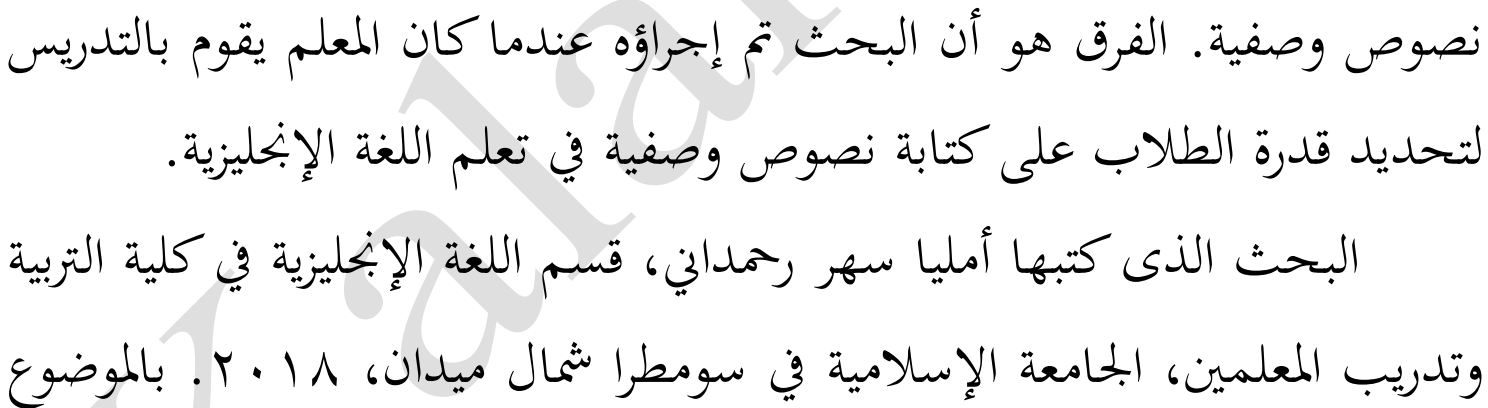

The Implementation Of Picture Word Inductive Model Toincreace The Students Ability In Writing Descriptive Text at Seventh Grade Of MTs Aziddin. Departement Of English Education Faculty Of Tarbiyah And Teacher. Training State Islamic University Of North Sumatra Utara. Medan على مهارة الكتابة نصوص وصفية. الفرق هو أن البحث تم إجراؤه عندما كان المعلم يقوم بالتدريس لتحديد قدرة الطلاب على كتابة نصوص وصفية في تعلم اللغة الإبخليزية. 
والجديد في هذا البحث هو أن البحث باستخدام الصوار والنماذج الإستقرائية

في الغالب استخدام لتعلم اللغة الإبخليزية. لذلك يريد المؤلف ححاولة استخدام نموذج التعلم هذا في تعلم اللغة العربية. مع الأخذ في الاعتبار أن قلة قليلة من الأشخاص قد بحثوا باستخدام هذا الصوار والنماذج الإستقرائية في تعلم اللغة العبية . لزيادة كيفية تعليم اللغة العربية تملك الكاتبة الحلّ ويدفع الى البحث فيها أعمق عن مسئلة في التعليم اللغة العربية باستخدام النماذج التي تساعد التلاميذ في التعليم

$$
\text { المفردات هي الصوار والنماذج الإستقرائية. }
$$

مع هذه المشكلة، تريد الكاتبة معرفة قدرة التلاميذ على الإنشاء الموجة

$$
\text { باستخدام الصوار والنماذج الإستقرائية. }
$$

تعليم المفردات امر ضروري في التعليم اللغة. خاصة في تعليم اللغة العربية.

واحد من صعب الطلاب في التعليم اللغة العربية يعني يستعيب الطلاب في ذكر وحفظ المفردات اللغة العربية' .

تعليم اللغة وبخاصة اللغة العربية في حاجة نماذج التعليم المناسبة الكافية ليكون التعليم غير ممل وجامد بل يكون نشاطا متعا. فيتضح التفاعل بين المدرس والتلاميذ أكثر فعاليا وابتكاريا وانتاجيا. نماذج التعليم من اهمية مكونات التى اهتمام لتعليم اللغة واستخدام الوسائل المالئمة دور في تحقيق التعليم الممتعا حتى تساعد في الوصول إلى أغراض مرسومة؛.

كثيرا من الامور الذي يجب أن ينظر المعلّم في تعليم اللغة العبية ، بما في ذلك

توفر التعليم كافية. بشكل عام الوسائل التعليمية تشمل الوسائل السمعية والبصرية. التعلم هو الأكثر فعالية وبتتذب بدعى من الوسائل الملائم. فعالية تستخدام

3 M Ilham Muchtar, "Peningkatan Penguasaan Mufradat Melalui Pengajian Kitab Pada Mahasiswa Ma'had AlBirr Unismuh Makassar," Jurnal: Al-Maraji' 2, no. 2 (2018): 13.

${ }^{4}$ Ade Arip Ardiansyah, "Trial Use of Inquiry Methods in Learning to Write Arabic in Junior High School Santi Asromo Majalengka," Alsuna: Journal of Arabic and English Language 3, no. 1 (25 Mei 2020): 56-65, https://doi.org/10.31538/alsuna.v3i1.706. 
Kalamuna, Vol. 1. No. 1, Januari 2022. 63 - 80

الوسائل في عملية التعلم فيما يتعلق بيوانب كثيرة، بما في ذلك المواد التى سوف

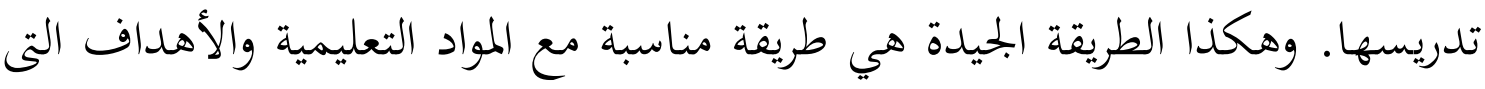

$$
\text { تحقيقها من خلال عملية. }
$$

بناء على مقابلات في الفصل احد عشر بمدرسة العالية الحكومية ليبك ربجكس بيتونج بانتين. متعلق تعلم اللغة العربية ، ان هناك بعض المشاكل من التلاميذ في مشاركة تعليم اللغة العربية ـ بما فيه : (1) عدم وجود الحماس عند تعلم المفردات، r) منخفض التلاميذ القدرة في المفردات العربية.

التعليم النماذج وفقا ايسجوني هي الاستراتيجية المستخدمة من بعض المعلمين

ليرفع الدافع الطلاب، قادرة على التفكير الناقد، تملك المهارات الاجتماعية، وتحقيق

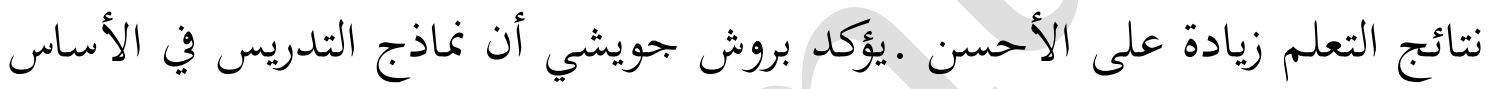
يمكن أن يساعد الطلاب على اكتساب المعلومات، فكرة، كفاية، قيمة، طريقة التفكير، وللتعبير عن أنفسهم ، نحن نعلمهم لمعرفة كيفية التعلم .

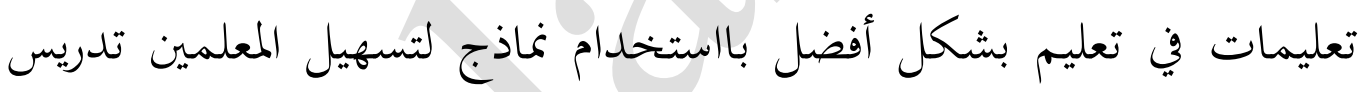
الطلاب. هناك كثير من النماذج واحد من النماذج في تعليم هو الصور والنماذج الاستقرائية. هناك كثير من نماذج التدريس لديها تاريخ طويل لا يزال يتم تطويرها من قبل المنشئ، واحد من النماذج عظيم فقط التي تعتبرها تحتاج إلى دخّلها في نماذج نئن التعليم. الصور والنماذج الاستقرائية هي واحد من استراتيجيات إضافة الثدريس الذي

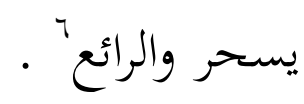
الصور والنماذج الاستقرائية في الواقع يحاول أن يفعل مدخل مباشرا لتطوير المفردات. اولا يطلب الطلاب قراءة وتلفّظ المفردات المتناثر في صورة .مسئلة في

${ }^{5}$ Abdul Aziz Rifa'at, "Stimulating You To Speak; A Strip Story As A Technique In Teaching Speaking," Elite: English and Literature Journal 5, no. 1 (15 Juni 2018): 12-21, https://doi.org/10.24252/elite.v5i1a2.

6 Fakturmen Fakturmen, "Metode Suggestopedia Dan Implikasinya Dalam Pembelajaran Bahasa Arab Keterampilan Mengarang (Insyā’)," Lisanan Arabiya: Jurnal Pendidikan Bahasa Arab 4, no. 01 (29 Juni 2020): 1-30, https://doi.org/10.32699/liar.v4i1.1037.

66 | Kalamuna: P-ISSN: 2655-4267, E-ISSN: 2745-6943 
التعليم باستخدام النماذج التي تساعد التلاميذ في التعليم المفردات هي الصور والنماذج الاستقرائية. الصور والنماذج الاستقرائية هي واحدة من استراتيجيات التدريس التى مثيرة جدا للاهتمام لتعلّم التلاميذ. الصور والنماذج الاستقرائية نموذج واحد من التدريس ذات التوجه البحث التي توجه التلاميذ ليتمّ وظائف التى كفى مركَب.

يتناول هذا الجزء من البحث عددا من الدراسات السابقة المتعلقة المناسبة

Implementasi " بالموضوع هذا البحث. إن هذه الدراسة فيها البحث ذات صلة منها Model Pembelajaran Picture Word Inductive Model Dalam Meningkatkan Keterampilan Menulis Bahasa Inggris Di Sekolah Menengah Pertama”. آمينة مدسة الثانوية الحكومية ا شونعي رايا اشيح شرقية. تشير نتائج في هذه الدراسة الى زيادة في المهارة الكتابة من قبل الطلاب. بعد المرحلة الأولى يقيمة

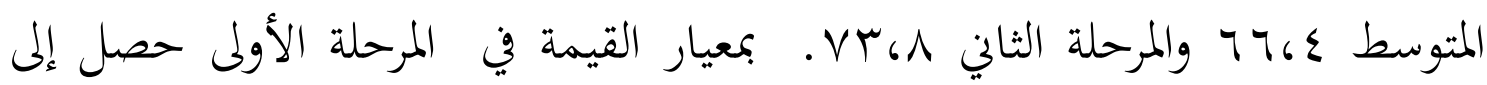

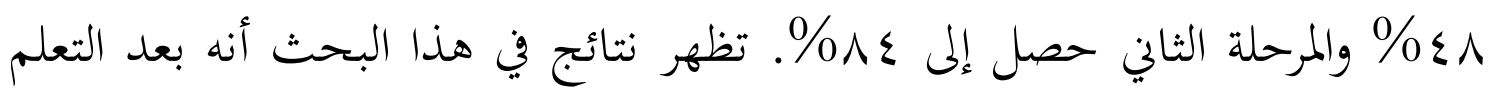
والتدريس باستخدام الصور والنماذج الأستقرائية يصبح الطلاب أكثر انتباها و نشاطا وسعادة ويمكن جذب اهتمام الطلاب في الفصل الأول رايا الدراسي العام الدراسي $r \cdot r \cdot \mid v-r \cdot 11$

قارن بالبحث الذي أرادت الباحثة بكثه فوجدنا أن المتغير المستقل في نفس الشكل يعني في تنفيذ وسائل الصور والنماذج الإستقرائية. وأما الفرق بين بحثي وبكثها فهو كان هذا البحث بحث بحريبي وأما بكثها هو بحث إجرائي صفي وان المتغير الصادى في هذا البحث هو قدرة التلاميذ على الإنشاء الموجه و المتغير الصادى في بكثها هو تطوير مهارة الكتابة الإبخليزية.

7 Sri Aminah, "Implementasi Model Pembelajaran Picture Word Inductive Model Dalam Meningkatkan Keterampilan Menulis Bahasa Inggris Di Sekolah Menengah Pertama,” Jurnal: Seuneubok Lada 6, no. 2 (2019): 13. 
على أساس حدث المشاكل، تقوم الكاتبة بكتابة البحث على التعلم

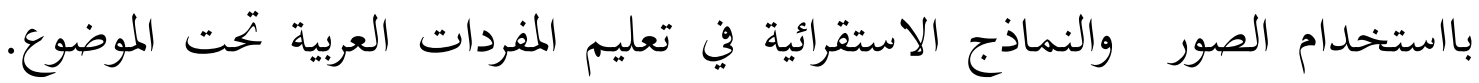

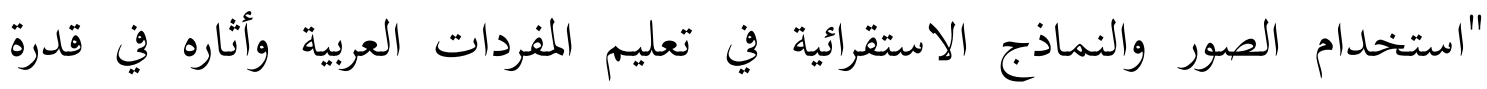

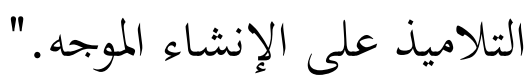

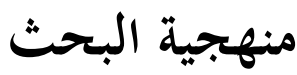

الطريقة المستخدمة في هذا البحث هي المدخل الكمي والطريقة التجريبية

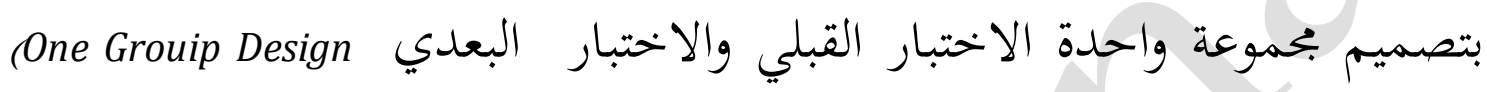

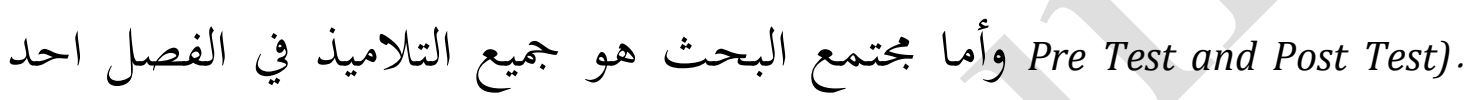
عشر بمدرسة العالية الحكومية ليبك ربنكس بيتونج بانتين عددهم عب تلميذا.

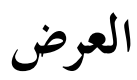

\section{مفهوم الصوار والنماذج الإستقرائية}

تعريف : الطريقة الاستقرائية، وهي أحد صور الاستدلال بحيث يكون سير

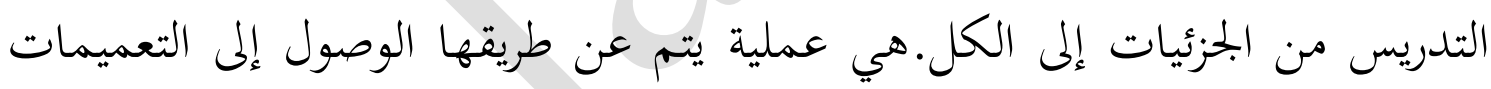

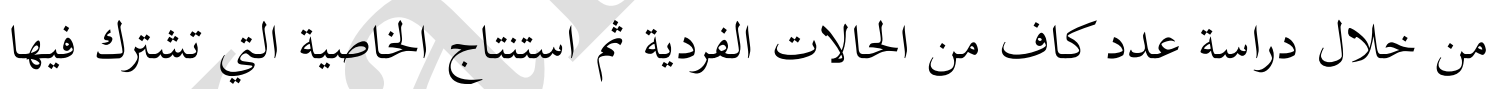

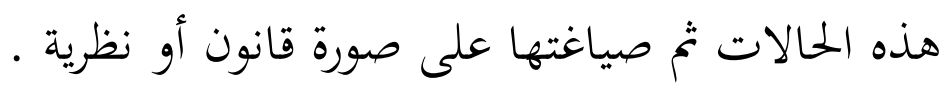

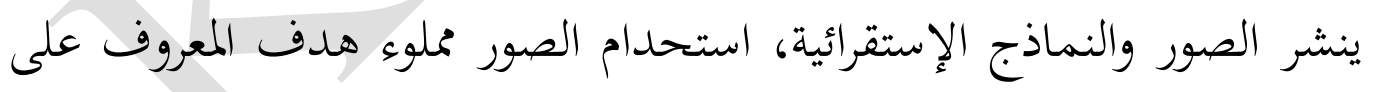

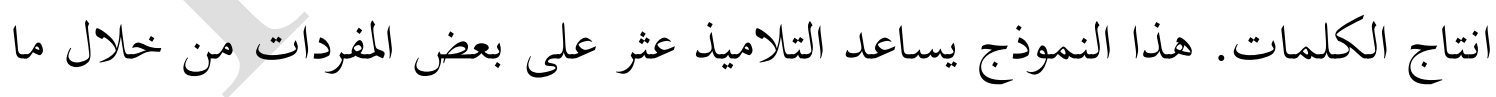
يقرأونه ونرى، والمفردات الذي كتاهم، ووجد المبدأ الصوتية وتركيبية في المفردات.

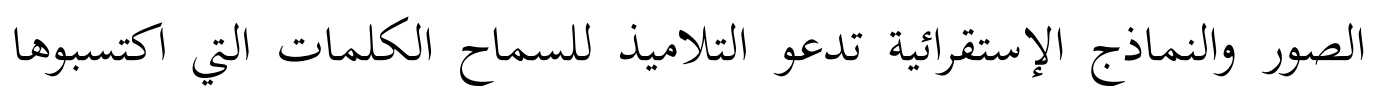

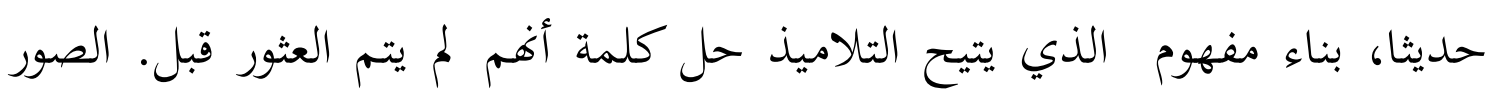

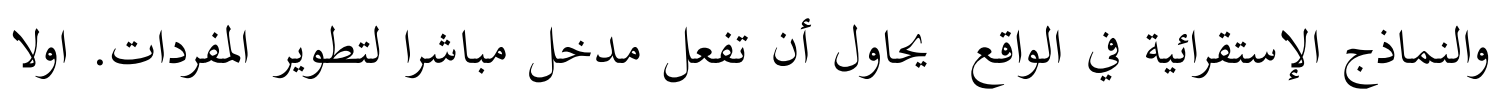
يطلب التلاميذ لقراءة وتلفّظ المفردات المتناثرة في صورة . 
تعليم المفردات التلاميذ على الإنشاء الموجه... (Acep Hermawan \& Ghisni Kautsar) أقر بأن تطوير المفردات هي مهم لترتفع مهارات القراءة والكتابة. الصور والنماذج الإستقرائية هي واحد من نموذج التدريس التعلم مع هذه جهود التنمية، التي تشمل كيف حفظ الكلمات وكيف عبارة الانتقال إلى الذاكرة طويلة المدي. اختصار، الصور والنماذج الإستقرائية الاستفادة من قدرة التلاميذ على التفكيرباستقرائيّ • فبانه يمكن التلاميذ الشّكل التعميم الذي يشكل أساس التحليل البنيوي والصوتيات. هذا يتعلق مع قدرهم في التفكير، ثم أولى المبدأ في هذا النماذج هو التلاميذ يملك القدرة لجعل هذا التعميم ووفي النّهاية يمكن أن يزيح معاهدة التحديث إليهـم.

اهداف استخدام الصور والنماذج الإستقرائية لينشر المفردات، الفكرة عن المفردات، الجمل وتركيبي الفقرة. القوة استخدام هذه الاستراتيجية هي أنه سوف

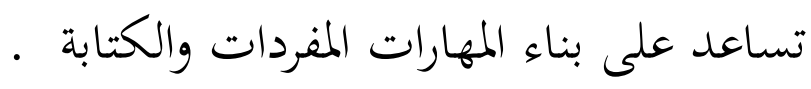
وجد استخدام هذا استراتيجيّة على جميع الفصل، بحموعة صغيرة، المزدوج او فرديّ، يوجّه التلاميذ يسأل عن المفردات وزيادة المفردات، عثر على المبدأ الصوتية وتركيبية، ويتورّط في النّشاط يقرأ ويكتب. بينما بضع المهارات يمكن أن تدرس بشكل واضح. الصور والنماذج الإستقرائية والوتدلإنتفع به قدرة التلاميذ لتفكير استقرائيّ. 
Kalamuna, Vol. 1. No. 1, Januari 2022. $63-80$

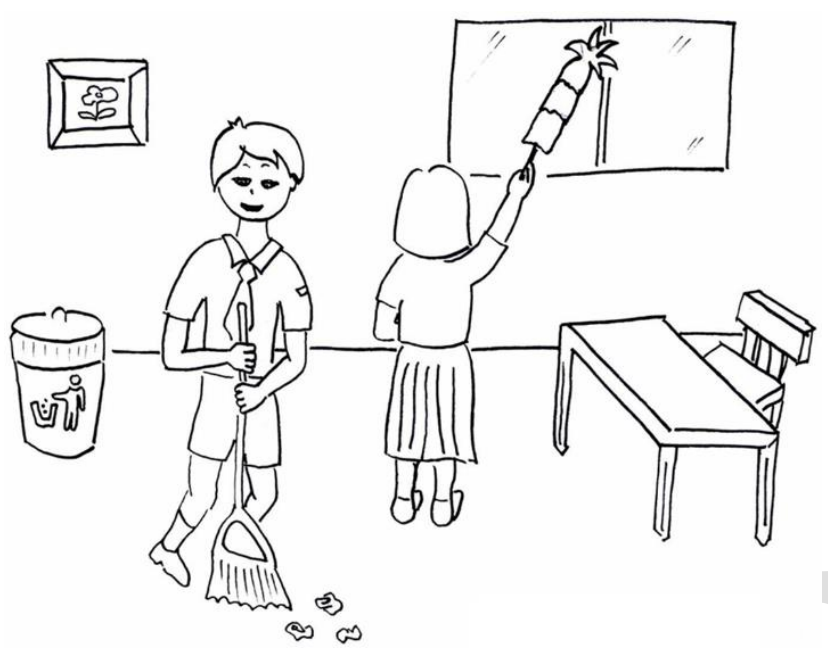

\section{الخطوات الصور والنماذج الإستقرائية}

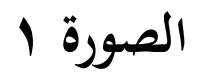

يبدأ التعليم بأن يكتب المفردات التي يروها في الصور. مثل المركز إلى صور الموره

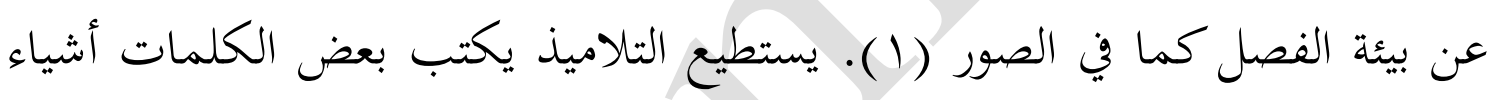

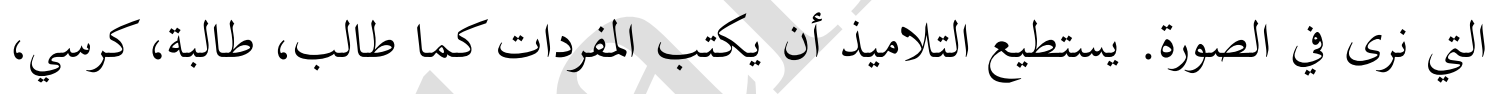

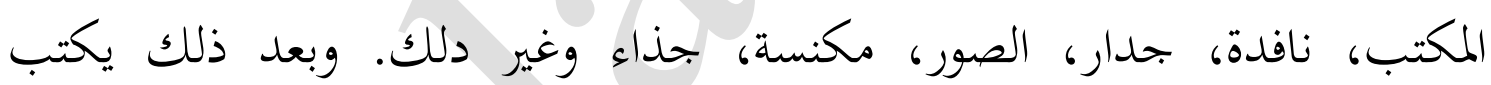
التلاميذ الجمل مثل تنظيف التلاميذ في الفصل وغير ذلك حتّى يساعد التلاميذ في تكوين الجمل. فيمايختصّ بما خطوات الصوار و النماذج الإستقرائية كمايلي:

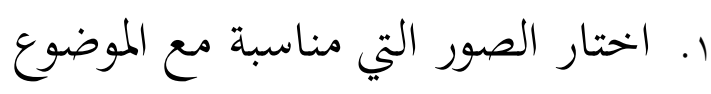

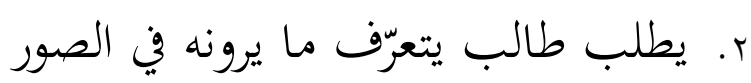

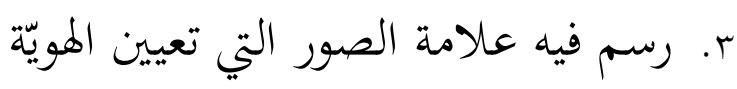

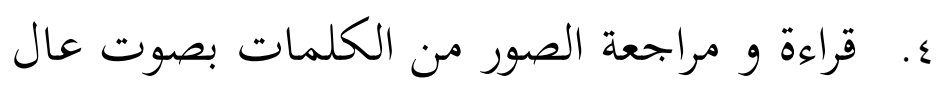


تعليم المفردات التلاميذ على الإنشاء الموجه... (Acep Hermawan \& Ghisni Kautsar) ه. يطلب طالب لقراءة المفردات (باستخدام خطوط على الرسم البياني عند الحاجة) لتوضيح المفردات الم بحموعة مختلفة. قراءة ومراجعة صورة (قراءة المفردات، يتهجأ

$$
\text { الكلمة وقراءة مرة أخرى) }
$$

ז. زيادة المفردات مساعد لتوضيح الموضيع

v. يوجّه التلاميذ لأوجد الموضوع لرسم البيان المفردات الصور. يطلب طالب لتفكير

$$
\text { على إعلام عن تريد ما يقولهم عن الموضوع. }
$$

^. يطلب طالب يكتب الجمل أو فقرة عن الرسم البيان المفردات الصور.يطلب التلاميذ يقسّم الجمل، حلّ به في المكان الجمل تكون فقرة جيّدة

$$
\text { 9. - ميقرأ ويراقب الجملة }
$$

إذا نستنتج، هذا الصور والنماذج الإستقرائية لغرض لكي جعل التلاميذ قادرين على بناء مهارات الطلبة في التفكير ويهدف لطلاب لفهم وزيادة المفردات في تعلم المفردات العربية.

\section{مفهوم تعليم المفردات العربية}

التعليم لغة هو عملية وطريقة التعليم لتجديب التلاميذ على الاهتمام بالتعلم، واصطلاحا إلقاء العلوم أو المهارات او المعلومات أو الخبرات من المدرس إلى التلاميذ^.

أما التعليم عند خالد بن حامد الحازمي هو اختص بما يكون بتكرير وتكثير حتى يهصل منه آثر في نفس المتعلم. قال عبد العليم إبراهيم. فالتعليم إذن من ألوان الخبرات الحيوية التى تستندفي تكوينها ونموها ونضجهاإلى أصول معينة وليس التعليم

${ }^{8}$ Acep Hermawan, Metodologi Pembelajaran Bahasa Arab (Edisi Revisi) (Bandung: Remaja Rosdakarya, 2018). 
من المحاولات العشوائية، أو الأعمال الاتجالية، التي تؤدي على أية صورة، دون ارتباط بقاعدة، أو تقييد بالنظام، أو أن التعليم نوع من المهارات العلميةج .

على الأحسن، في تعليم المفردات تبدأ بالمفردات الأساسية السهلة. قال أحمد

فؤاد إيفندي إن المرحلة وأسلوب تعليم المفردات أوخبرة التلاميذ في معرفة المعنى . 'ا هي ما يلي:

ا. . استماع المفردات، وهذا، مرحلة أولى لإعطاء الفرصة على التلاميذ لاستماع الكلمة. وإذا كان مكون الأصوات من الكلمة مستوعبة فالآتي كان التلاميذ يقدرون على الإستماع صحيحا.

r. ت تعبير الكلمة في هذه المرحلة كان المدرس يعطى الفرصة على التلاميذ لتعبير الكلمة المسموعة، وتعبير الكلمة الجمديد يقدرعلى مساعدة التلاميذ في ذاكرة

$$
\text { الكلمة في وقت طويل. }
$$

r. ب الحصول على معنى الكلملة، في هذه المرحلة، يلزم على المدرس أن يتلافي

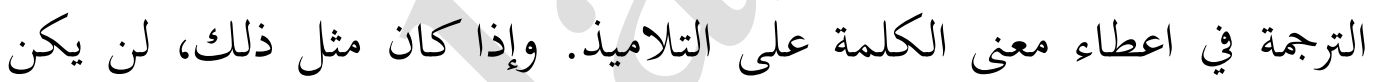
هناك الإتصال المباشري اللغة المدروسة. وأما معنى الكلمة المدروسة سينسوها التلاميذ سريعة. وهناك عدة الأساليب التي تقدر المدرس على استخدامها ليتلا في الترجمة للحصول على معنى الكلمة وهي باعطاءسياق الكلمة والتعريف البسيط واستخدام الصورة والمرادف والضد ونظر الأشياء الحقيق أو الصنعية وعرض حركة الجسم و الترجمة كآلة اختيارة آخرة إذا كانت الكلمة صعبة لفهمها.

\footnotetext{
9 Taufik Luthfi, "Hubungan Mata Pelajaran Muatan Lokal Bahasa Arab Terhadap Kemampuan Baca Tulis AlQuran Pada Siswa Kelas IX (Sembilan) SMP Al-Ihsan," Kalamuna: Jurnal Pendidikan Bahasa Arab dan Kebahasaaraban 2, no. 2 (1 Juli 2021): 76-89, https://doi.org/10.52593/klm.02.2.05.

${ }^{10}$ Ahmad Fuad Effendy, Metodologi Pengajaran Bahasa Arab (Malang: Misykat, 2005).
} 
تعليم المفردات التلاميذ على الإنشاء الموجه... (Acep Hermawan \& Ghisni Kautsar) ع. ـالقراءة اللفظية، بعدأن يقوم بمرحلة الاستماع والتعبير وفهم معان المغردات الجلديد والمدرس يكتبوهافي السبوة، والتلاميذلهم الفرصة لقراءها بصوت عالية. ه. كتابة الكلمة، إن استيعاب المفردات عند التلاميذ يكون مساعد إذاكان التلاميذمتطلبون لكتابتها وذاكرة خصائص الكلمة.

4. صناعة الكلمة، هذه من المرحلة الآخرة في تعليم المفردات هي استخدام الكلمة الجلديدة في الجملة المفيدة لساناأوكتابة.ويلزم على المدرس أن يكون ابتكاريا في اعطاء المثال باالكلمة المتنوعة والتلاميذ يتطلبون أن يتبعوها. ووفي تركيبها، يلزم على المدرس أن يستخدم الكلمة الإنتاجية ليكون التلاميذ ساهلين في فهمها.

\section{اهداف تعليم المفردات العربية}

من المعلوم أن المفردات عنصر من عناصر اللغة التي تلزم أن توجه في المتعلم الأجنبي وحاصة اللغة العربية. فمفردات اللغة العربية الكافية تدعم الفرد في الاتصال والقراءة والكتابة بها. لذلك أن مهارة اللغة (التكلم والقراءة والكتابة) يلزم أن بعضدها المعرفة واستيعاب المفردات الكثيرة والإنتاجية والواقعية. كانت زيادة مفردات الفرد أمر هام في عملية تعليم اللغة واستيعاب قدرته على اللغة المستوعبة. يدرس التلاميذ المغردات الجمديدة في المدرسة مادة خاصة، وكثير من الأفراد الذين يظنون أن تشكيل المفردات عملية اجتذابية وتربوية. لذلك يحتاج إلى الطريقة المناسب في تعليم المفردات العربية للوصول إلى مغردات اللغة المحتاجة في تعليم اللغة العربية.

11 Nur Fitri dan Siti Uriana Rahmawati, “Atsar Istikhdam Murabba' Al-Kalimat Fi Ta'lim Mufradat Wa Ta'allumiha," Arabiyat: Jurnal Pendidikan Bahasa Arab dan Kebahasaaraban 4, no. 1 (28 Juni 2017), https://doi.org/10.15408/a.v4i1.5326. 
Kalamuna, Vol. 1. No. 1, Januari 2022. $63-80$

من البيان السابق تستنتج الكاتبة أن أهداف تعليم مفردات اللغة العربية هي إعطاء المعرفة للتلاميذ في المفردات المعينة، وممارسة التلاميذ لقدرة على استخدام

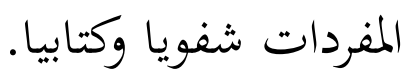

\section{خطوات تعليم المفردات العربية}

وقال أئيف سيف الرحمن إن الخطوات في تعليم المفردات هي استماع المفردات

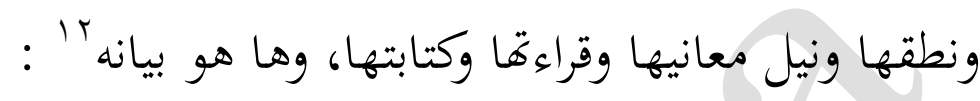
ا. استماع المفردات

يتيح المدرس للتلاميذ لاستماع المفردات المنطوقة بالمدرس الوسائل، كلمة

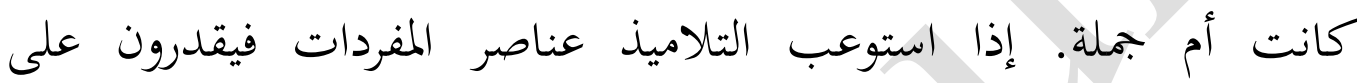
استماعها صحيحا.

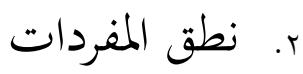

يتيح المدرس على التلاميذ لنطق المفردات المسموعة لأنه يساعد التلاميذ إلى

$$
\text { r. تذكير المفردات. }
$$

في هذه الخطوة، يجتنب المدرس ترجمة المفردات عند إعطاء معاني المفردات للتلاميذ، لأفا لا توجد الاتصال المباشر في اللغة المدروسة. هناك أساليب

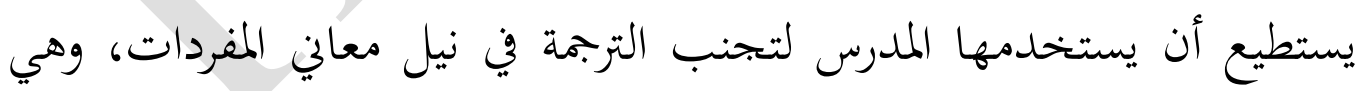
بإعطاء سياقات المفردات والتعاريف القصيرة واستخدام الصور والترادف

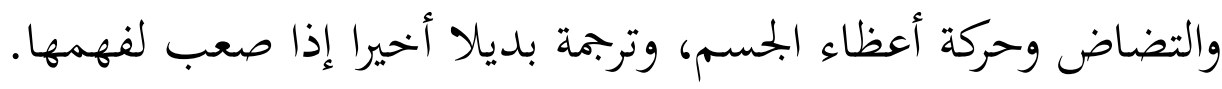

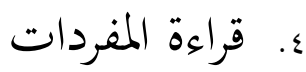

12 Aep Saepurrohman dan Siti Laela Nurhayati, "Istikhdām Uslūb Al Ghinā Fī Ta'līm Al Mufradāt Al 'Arabiyyah Li Tarqiyati Qudrah Al Talāmīdz 'Alā Alhiwār Al 'Arabī,” Ta'lim al-'Arabiyyah: Jurnal Pendidikan Bahasa Arab \& Kebahasaaraban 3, no. 2 (3 Mei 2020): 175-93, https://doi.org/10.15575/jpba.v3i2.7715. 
تعليم المفردات التلاميذ على الإنشاء الموجه... (Acep Hermawan \& Ghisni Kautsar)

بعد استماع التلاميذ المفردات ونطقها وفهمها فيكتب المدرس المفردات على السبورة، ويتح على التلاميذ لقراءة المفردات جهريا. ه. متابة المفردات

كان استيعاب التلاميذ على المفردات يساعد إلى كتابة المفردات الجلديدة

$$
\begin{aligned}
& \text { الملدروهة، لأها لم تزل تذكيرها في أفكارهم. } \\
& \text { 1. بكمل الجملة }
\end{aligned}
$$

الخطوات في تعليم المفردات هي استخدام المفردات الجمديدة في جملة مفيدة شفويا وكتابيا.

فالخطوات في تعليم المفردات الجحديدة عند محمد على الخولي هي ينطق المدرس المفردات والتلاميذ يستمعون، من الافضل أن يكررها مرتين أو ثلاثنا، ويكتب المدرس المفردات على السبورة مشكولة شكالا كاملا، ويعرض المدرس معنى المفردات بالطريقة التي يراها مناسبة، ويستخدم المدرس المفردات في جملة واحدة أو أكثر لتضيح وظيفة المفردات نحويا، ويكرر التلاميذ إحدى الجمل تكررا جميعا وفرديا، ويرشد المدرس تلاميذا إلى طريقة كتابة المفردات المكتوبة في السبورة، ويكتب المدرس على السبورة معنى المفردات، ويقرأ التلاميذ قائمة المفردات الجمديدة المكتوبة على السبورة أمامهم، ويكتبون معاغا والجمل التوضيحية في دفاترهم. مفهوم الإنشاء الموجه 


$$
\begin{aligned}
& \text { مفهوم الإنشاء من ناحية اللغة هي الشروع والإيجاد والصنع. ويرى صاحب } \\
& \text { "الخصائص": أن الإنشاء لفظا هو الإبانة والإفصاح كما يحاول في خاطر الإنشاء من } \\
& \text { أفكار ومشاعد بكيثث يفهمه الأخرون. \& } 1 \\
& \text { وأما الإنشاء إصطلاحسا فهناك أراء كثيرة، منها } 10
\end{aligned}
$$

ا. قال الدكتور نايف معروف: هو العمل المدرسي المنهجي الذي يسير وفق خطية متكاملة من ترجمة أفكاره ومشاعده وأحاسيسه ومشاهداته وفق تسبق فكرى

r. قال أحمد هاشمي هو : علم يعرف به كيفية استنباط المعلني وتأليفها مع الإنشاء منها بلفظ لائق بالمقام وهو مستمد في كل المباحث ويعتمد الإنشاء في كل

$$
\text { المعارف البشرية. }
$$
r. وقال أيضا زين الدين : هو ما حصله المؤلف من تعبير الفكرة مع اعتماده على الدليل أو البرهان والمشاهدة أو بتجريبات الكاتب المنظمة ( السستيماتيكية).

بعد أن نظرت الباحثة إلى الأراء السابقة استنتجت بأن الإنشاء هي طريقة لتظهير ما في نفس مؤلف من فكرة وحواسه إما بلسانه (الكالام) أو قلمه (الكتابة) حتى يصير قصة أو مؤلفا يجذب قارئ بقراءته وسامعا بسماعهة 17 من المعروف أن الإنشاء الموجه هو فرع من الإنشاء التحريري أو التغيير

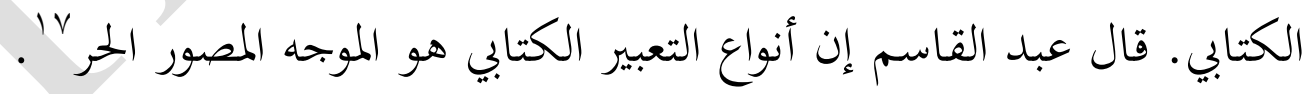

14 Dihyatun Masqon, Yoke Suryadarma, dan Achmad Farouq Abdullah, "Analisis Problematika Pembelajaran Insya' Arabi at-Tahriri Santri Kelas Lima Kulliyatul Mu'allimin Al-Islamiyah (KMI) Di Pondok Modern Gontor Dua," At-Ta'dib 12, no. 2 (29 Desember 2017): 139, https://doi.org/10.21111/at-tadib.v12i2.1100.

15 Odi Kosdian, "Improving Students Speaking Skill By Using Picture Strip Story," Indonesian EFL Journal 2, no. 2 (2017): 100, https://doi.org/10.25134/ieflj.v2i2.642.

16 Juhaeti Yusuf, Ahmad Zaki Alhafidz, dan Muhammad Fahmi Luthfi, "Menulis Terstruktur Sebagai Urgensi Pembelajaran Maharah Al-Kitabah," An Nabighoh: Jurnal Pendidikan dan Pembelajaran Bahasa Arab 21, no. 02 (31 Desember 2019): 203, https://doi.org/10.32332/an-nabighoh.v21i02.1683.

17 Abdul Kosim, "Penggunaan Media Visual Dalam Pembelajaran Muthola'ah Untuk Meningkatkan Ketrampilan Berbicara Santri Kelas VIII SMPIT Kharisma Darussalam," Kalamuna: Jurnal Pendidikan Bahasa Arab dan Kebahasaaraban 2, no. 2 (1 Juli 2021): 26-41, https://doi.org/10.52593/klm.02.2.02. 
تعليم المفردات التلاميذ على الإنشاء الموجه... (Acep Hermawan \& Ghisni Kautsar) قد شلكين و هروين أن الإنشاء الموجه من المصطلح المستعمل الآن لتصوير تعليم الكتابة، أينما فصل التعليم مقررا في كل يوم كي يورط التلاميذ في عملية الكتابة. كما نقل شلكين وهروين أن الإنشاء الموجه هو من إحدى طرق التعليم التي الطلبة والمحاضر لأن يقوم بالتفكير،وكان ذلك التفكير ححتاجا للتعبير. وترتيب الإنشاء الموجه تركيب وصفي يتكون من الإنشاء الموجه. وأما لفظ الإنشاء فمصدر من أنشأ - ينشئ - إنشاء ومعناه ركب أو ألف. (المنور: IV I I ) ومعناه الإصطلاحي فمن يعمل به بميع المعاني والتأليف بينهما وتنسيقها ثم تعبير عنها بعبارات أدبية بليغة. وأما كلمة "الموجه" فكانت مشتقة من وجحه يوجه توجيها موجه ومعناه : فعل على جهة واحدة لا يختلف. (المعجم الوسيط: 1 ( 1 ). ومن البيان السابق ترى الكاتبة أن الإنشاء الموجه أوجد التعبير الذي يوجه إلى جهة معينة التي يعطيها المحاضرالطلبة توجيها في كتابة الإنشاء. ويكون التوجيه متنوعا وسيأتي بحثه.

واقعية قدرة التلاميذ في تعليم المفردات العربية وآثره على الإنشاء الموجه قبل استخدام الصور والنماذج الإستقرائية لمعرفة واقعية قدرة التلاميذ على الإنشاء الموجه قبل استخدام الصور والنماذج الاستقرائية. واقعية قلرة التلاميذ على الإنشاء الموجه في تعليم المفردات قبل استخدام الصور والنماذج الاستقرائية تدل على درجة منخفصة بتوزيع البيانات المعتدلة. هذا يتحقق بقيمة الم لأكا قيمة المتوسط على بم. . . وهي تكون بين . ع-. معيار التفسير. 
Kalamuna, Vol. 1. No. 1, Januari 2022. $63-80$

واقعية قدرة التلاميذ في تعليم المفردات العربية وآثره على الإنشاء الموجه بعد استخدام الصور والنماذج الإستقرائية

لمعرفة واقعية قدرة التلاميذ على تعليم المفردات وآثره على الإنشاء الموجه بعد استخدام الصور والنماذج الإستقرائية. واقعية قدرة التلاميذ على الإنشاء الموجه في تعليم المفردات بعد استخدام الصور والنماذج الاستقرائية تدل على مستوى جيدجدا بتوزيع البيانات المعتدلة. هذا يتحقق بقيمة المتوسط المحصولة على قدر هـ ـ.بم وهي

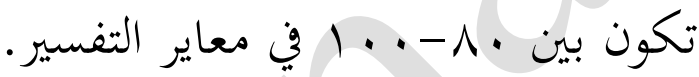

واقعية آثر استخدام الصور والنماذج الإستقرائية في تعليم المفردات العربية في قدرة التلاميذ على الإنشاء الموجه ولمعرفة آثار استخدام الصور والنماذج الاستقرائية في تعليم المفردات العربية في قدرة التلاميذ على الإنشاء الموجه. واقعية المقارنة بين قدرة التلاميذ على الإنشاء الموجه في تعليم المفردات بعد استخدام الصور والنماذج و بعد تطبيقه تدل على

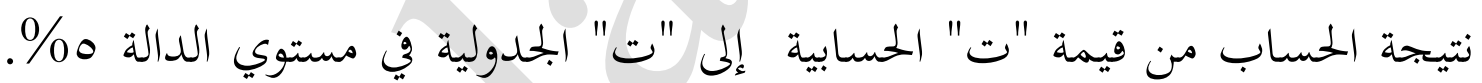

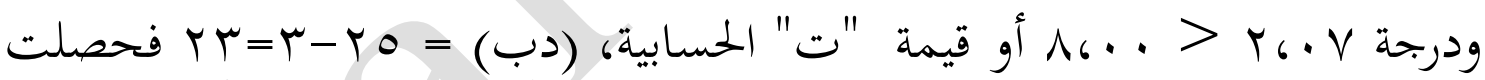
قيمة "ت" الجدولية أكبر من قيمة "ت" الجحدولية. فتدل هذه النتيجة على أن الفرضية مقبولة بمعنى أن استخدام الصور والنماذج الاستقرائية في تعليم المفردات العربية في قدرة التلاميذ على الإنشاء الموجهه.

\section{خاتمة البحث}

والنتائج المحصولة عليها من هذا البحث هي أن قدرة التلاميذ على الإنشاء الموجه الفصل الحادى عشر ليبك ربنكس بيتونج بانتين في تعليم المفردات العربية قبل استخدام الصور والنماذج الإستقرائية تدل على درجة "منخفضة" بقيمة المتوسط 
سم، ، ه . واما قدرة التلاميذ على الإنشاء الموجه بعد استخدام الصور والنماذج الإستقرائية تدل على درجة "جيد جدا" بقيمة المتوسط . 06مرم. واما ترقية القدرة فتدل عليها قيمة "ت" الحسابية إلى "ت" الجلدولية في مستوى الدالة ه\%٪. ودرجة

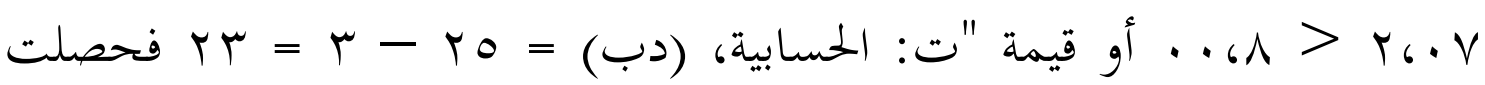
قيمة "ت" الجلدولية أكبر من قيمة "ت" الجحدولية. واستخدام الصور والنماذج الإستقرائية في تعليم المفردات العربية يؤثر في قدرة التلاميذ على الإنشاء الموجه.

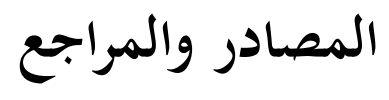

Aminah, Sri. “Implementasi Model Pembelajaran Picture Word Inductive Model Dalam Meningkatkan Keterampilan Menulis Bahasa Inggris Di Sekolah Menengah Pertama." Jurnal: Seuneubok Lada 6, no. 2 (2019): 13.

Ardiansyah, Ade Arip. "Trial Use of Inquiry Methods in Learning to Write Arabic in Junior High School Santi Asromo Majalengka." Alsuna: Journal of Arabic and English Language 3, no. 1 (25 Mei 2020): 56-65. https://doi.org/10.31538/alsuna.v3i1.706.

Effendy, Ahmad Fuad. Metodologi Pengajaran Bahasa Arab. Malang: Misykat, 2005.

Fakturmen, Fakturmen. "Metode Suggestopedia Dan Implikasinya Dalam Pembelajaran Bahasa Arab Keterampilan Mengarang (Insyā')." Lisanan Arabiya: Jurnal Pendidikan Bahasa Arab 4, no. 01 (29 Juni 2020): 1-30. https://doi.org/10.32699/liar.v4i1.1037.

Fitri, Nur, dan Siti Uriana Rahmawati. "Atsar Istikhdam Murabba' Al-Kalimat Fi Ta'lim Mufradat Wa Ta'allumiha." Arabiyat: Jurnal Pendidikan Bahasa Arab dan Kebahasaaraban 4, no. 1 (28 Juni 2017). https://doi.org/10.15408/a.v4i1.5326.

Hermawan, Acep. Metodologi Pembelajaran Bahasa Arab (Edisi Revisi). Bandung: Remaja Rosdakarya, 2018.

Kosdian, Odi. "Improving Students Speaking Skill By Using Picture Strip Story." Indonesian EFL Journal 2, no. 2 (2017): 100. https://doi.org/10.25134/ieflj.v2i2.642.

Kosim, Abdul. "Penggunaan Media Visual Dalam Pembelajaran Muthola'ah Untuk Meningkatkan Ketrampilan Berbicara Santri Kelas VIII SMPIT Kharisma Darussalam." Kalamuna: Jurnal Pendidikan Bahasa Arab dan Kebahasaaraban 2, no. 2 (1 Juli 2021): 26-41. https://doi.org/10.52593/klm.02.2.02. 
Luthfi, Taufik. "Hubungan Mata Pelajaran Muatan Lokal Bahasa Arab Terhadap Kemampuan Baca Tulis Al-Quran Pada Siswa Kelas IX (Sembilan) SMP AlIhsan." Kalamuna: Jurnal Pendidikan Bahasa Arab dan Kebahasaaraban 2, no. 2 (1 Juli 2021): 76-89. https://doi.org/10.52593/klm.02.2.05.

Masqon, Dihyatun, Yoke Suryadarma, dan Achmad Farouq Abdullah. "Analisis Problematika Pembelajaran Insya' Arabi at-Tahriri Santri Kelas Lima Kulliyatul Mu'allimin Al-Islamiyah (KMI) Di Pondok Modern Gontor Dua.” At-Ta'dib 12, no. 2 (29 Desember 2017): 139. https://doi.org/10.21111/at-tadib.v12i2.1100.

Muchtar, M Ilham. "Peningkatan Penguasaan Mufradat Melalui Pengajian Kitab Pada Mahasiswa Ma'had Al-Birr Unismuh Makassar.” Jurnal: Al-Maraji’ 2, no. 2 (2018): 13.

Rifa'at, Abdul Aziz. "Stimulating You To Speak; A Strip Story As A Technique In Teaching Speaking." Elite: English and Literature Journal 5, no. 1 (15 Juni 2018): 12-21. https://doi.org/10.24252/elite.v5i1a2.

Saepurrohman, Aep, dan Siti Laela Nurhayati. "Istikhdām Uslūb Al Ghinā Fī Ta'līm Al Mufradāt Al 'Arabiyyah Li Tarqiyati Qudrah Al Talāmīdz 'Alā Alhiwār Al 'Arabī." Ta'lim al-'Arabiyyah: Jurnal Pendidikan Bahasa Arab \& Kebahasaaraban 3, no. 2 (3 Mei 2020): 175-93. https://doi.org/10.15575/jpba.v3i2.7715.

Yusuf, Juhaeti, Ahmad Zaki Alhafidz, dan Muhammad Fahmi Luthfi. "Menulis Terstruktur Sebagai Urgensi Pembelajaran Maharah Al-Kitabah.” An Nabighoh: Jurnal Pendidikan dan Pembelajaran Bahasa Arab 21, no. 02 (31 Desember 2019): 203. https://doi.org/10.32332/an-nabighoh.v21i02.1683. 